\title{
Explorations of Geocaching in the Virtual World of Second Life
}

\section{Cecilia Lam}

School of Interactive Arts \&

Technology,

Simon Fraser University

250 - $13450102^{\text {nd }}$ Avenue

Surrey, BC, Canada

csl21@sfu.ca

\section{Carman Neustaedter}

School of Interactive Arts \&

Technology,

Simon Fraser University

$250-13450102^{\text {nd }}$ Avenue

Surrey, BC, Canada

carman_neustaedter@sfu.ca

\begin{abstract}
Geocaching is a location-based game where players search for physical containers in the real world using GPS coordinates. Over the past twelve years, Geocaching has grown to include over 1.5 million players. In addition to real world Geocaching, this game has also extended into virtual worlds like Second Life. In this paper, we document our explorations of Geocaching in Second Life. Here we compare it to Geocaching in real life and describe the likely reasons why the game has not created a player base that is as active as real world Geocaching.
\end{abstract}

\section{Author Keywords}

Second Life; geocaching; virtual worlds; online games

\section{ACM Classification Keywords}

H.5.3. Information interfaces and presentation: Group and Organization Interfaces - Computer Supported Cooperative Work;

\section{Introduction}

Geocaching is a location-based game that has seen remarkable success since its inception in 2000. This is evidenced by the game's growth to include over 1.5 million players and over 5 million hidden geocaches worldwide. Given its popularity, people have extended the game of Geocaching into other environments, 
including virtual worlds and massively multiplayer online games. For example, the web site, "SL Geocaching" [5] has recorded geocaches placed in the virtual world of Second Life (SL) since the year 2007. Despite such extensions, we know little of how Geocaching is constructed in virtual worlds and how players actually participate. To better understand this, we explored Geocaching in Second Life through active participation in the game and interviews with two SL geocachers.

\section{Related Work}

Geocaching is a GPS-enabled treasure hunt that takes place in the real world. In Geocaching, players hide physical containers (e.g., film canisters, repurposed ammunition containers, tupperware) with a logbook and post the GPS coordinates of the container on Geocaching.com. Other players then use the coordinates to find the physical container.

Studies have revealed that players participate in Geocaching because they want to enjoy nature, get exercise, experience new places, compete with other geocachers, improve online statistics, etc. [1][4]. We also know that the game of Geocaching is largely successful because of its content-generation model. In Geocaching, players themselves create the game content through a flexible yet well-defined structure [2]. This content-creation model has caused the game to grow to include a large volume of content, accessible around the world [3]. It has also meant that players have formed a "community" that includes customs for hiding and finding geocaches [2]. This makes the game of Geocaching recognizable and understood by players regardless of their location in the world [2].

\section{Study and Exploration Method}

We conducted an exploratory study of Geocaching in Second Life to understand how the game is structured and played as it compares to Geocaching in the physical world. Once a week, the primary author participated in Geocaching sessions for 2 - 5 hours per week over a period of three months. During each session, she hunted for geocaches in SL. Sometimes caches took multiple tries to find, involving several hours of searching. Some caches could not be found and we suspect they were no longer available. In total, the primary author found five geocaches and hunted for a total of 11 caches. These numbers highlight the challenging nature of Geocaching in SL and also the unavailability of many geocaches in the environment.

To supplement our knowledge of the activity, the investigator also read postings about SL Geocaching in online forums and conducted observations and interviews with two existing SL geocachers, contacted through the online forums. Both interviewees went Geocaching with the primary author in SL and answered questions during their searching activities. Questions focused on understanding their motivations for Geocaching, what strategies they used for finding geocaches, and how Geocaching in SL was structured. Next we report on several of the key themes that emerged from our analysis of our activities and interviews.

\section{Geocache Placement and Containers}

Geocache placement in SL largely models Geocaching in real life, in an effort to model the game fairly closely. In this way, Geocaching is still the same basic game regardless of the change from the physical world to a virtual world. Containers are hidden near foliage or 


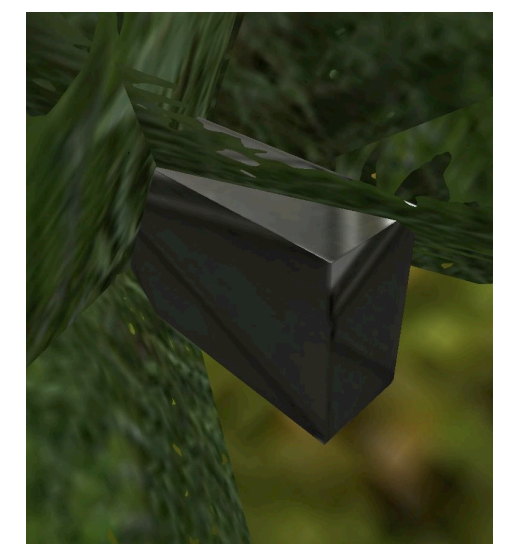

Figure 1. A traditional cache using a 'repurposed' ammunition container placed under some ferns in Second Life.

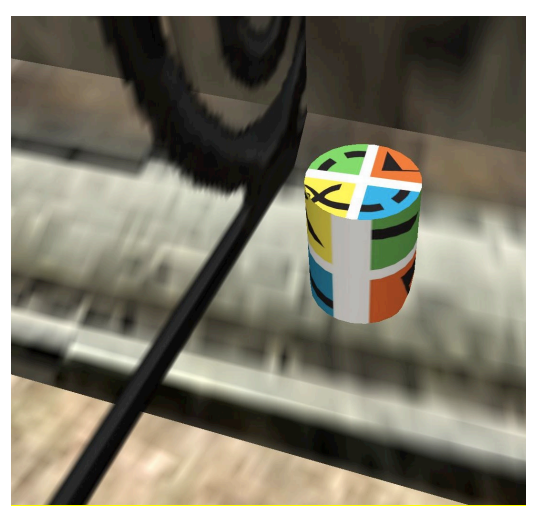

Figure 2: A micro cache, about the size of a film canister, is placed at the foot of a column in Second Life. buildings, often concealed in camouflage materials (Figure 1). The standard containers for geocaches in SL are usually grey ammunition containers, much like real life Geocaching (Figure 1). Although other sizes are discouraged in the SL Geocaching site, some geocachers create micro-caches (Figure 2), again, similar to Geocaching in the physical world.

Unlike Geocaching in real life where the community of players can take part in maintaining geocaches and updating prizes (e.g., SWAG) [2], the act of updating geocaches in $S L$ is bound to the player who creates and places the geocache. This is because of the content creation structure in SL where virtual world objects are created by a single player who is the only person with permissions to modify it.

Geocaching in SL is also further restricted because in order to create virtual world content, you must construct it on land that you own (which can be purchased for real money). If ownership of the land changes, the new owner becomes the new caretaker of the geocache. This also means that caches cannot be accidently destroyed or removed by geocache hunters or 'muggles', which is the case in the physical world. Although there is 'public land' in SL where one could create and place geocaches, items placed there decay after 24 hours. Thus, geocaches that might have been placed on public land may no longer exist. This was a major challenge we faced when hunting for geocaches; many that we looked for were no longer present.

Sometimes, the decay time limit is used creatively for 'event caches.' For example, some players set up geocaches in public land and make an announcement informing others of the event. Other players then work together or individually to find the geocaches before the 'decay time' runs out and the caches disappear.

\section{Geocache Searching}

As $S L$ is a virtual world, geocache searching can be performed anytime, regardless of weather conditions or physical disabilities. The act of searching for geocaches in $S L$ is very similar to Geocaching in real life. A set of coordinates within SL is given out online (at [5]) as a starting point and the geocaches are often within a short distance of that location. Players can teleport to locations close to this point, walk there, or fly (these are the existing travel methods in $\mathrm{SL}$ ).

Once arriving in an area, however, we learned that similar to real life Geocaching, geocaches can be difficult to visually spot and find. For example, Figure 1 shows an ammunition container hidden under some ferns. To find the cache, one must adjust her camera angle and position within SL in order to see the cache. This may need to be done repeatedly as one moves throughout the environment. Such acts are not as simple as tilting one's head in real life, given the interaction controls in SL. Thus, without the right camera angles, it can be difficult to find a geocache, even if you have hints from logs that others have left.

Network and graphics lag can also hinder one's searching efforts. If the land that a geocache is placed on is very populated, a player may 'turn down' their graphics to a 'low' setting to allow builds to load faster and reduce lag. At the same time, this means that small items may not be graphically rendered. Thus, geocache searching also involves adjusting one's rendering quality during the hunt, and sometimes 


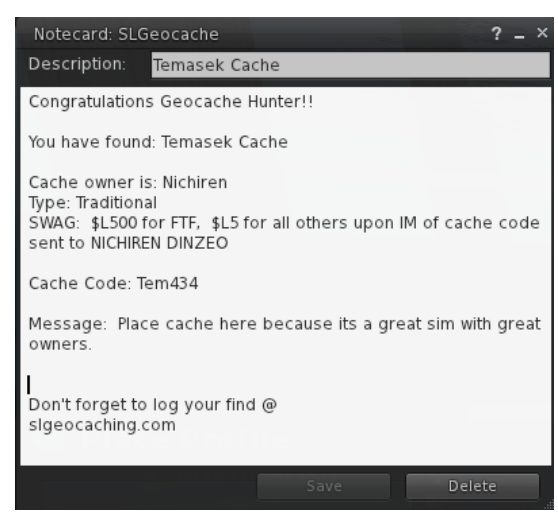

Figure 3. A notecard from a geocache posted on slgeocaching.com. dealing with loading lag. This may even induce boredom as a scene is rendered.

Players' vision can also be limited to a certain range, depending on the location, where not everything is shown to a user all at once. As you head in a certain direction, more details appear allowing you to see the texture, colour, and shape of objects and not just their bounding boxes. This means that unlike Geocaching in real life, it can be more difficult to spot a likely 'cache hide' location from a distance.

Once a geocache is found, unlike Geocache containers in real life, there are no paper logs for players to write their name in. Instead, a notecard, similar to the one shown in Figure 3 appears. This lists the cache, the type of cache, and it's reward (often Linden dollars or $\mathrm{SL}$ objects), if any. There may also be a message stating the reason why the cache was placed there. Players can log their find on the SL Geocaching site.

\section{Motivations for Searching and Hiding}

The players we talked to and the forums we read indicated that Geocaching in SL provides yet another activity that people can do in the virtual world. Sometimes it relieves boredom and other times people are motivated for the small monetary rewards. One interviewee could no longer cache in real life because of a physical injury, so she turned to SL.

Like Geocaching in $\mathrm{RL}$, many geocaches are placed to bring people to a particular location. However, in SL, this may be considered more of a business strategy. Many pieces of private land are owned to setup a business such as a clothing store, bar, etc. Having a geocache at these places may increase the visitor count and chance that people will buy items. Some locations in $\mathrm{SL}$ are related to real life businesses and their advertisements and objects may lead you to the company's online website. Again, this is a way of luring customers.

\section{Conclusion}

Our study has documented the ways in which Geocaching occurs in Second Life. We found very few geocachers around in the environment and many geocaches that were no longer there. Our analysis of the environment and geocaching activities shows this is likely because of restrictions placed on the creation of geocaches on private land, along with challenges in finding the geocaches due to rendering and lag.

\section{Acknowledgements}

We thank Jason Procyk, Jessica Coccimiglio, and Victoria Moulder for their thoughts on this work. This work was funded by the Social Sciences and Humanities Research Council of Canada.

\section{References}

[1] Chavez, D.J., Courtright, R., and Schneider, I. Over the River and through the Woods, Parks \& Recreation, 39, 4 (2004), 68-72.

[2] Neustaedter, C., Tang, A., and Judge. T, The Role of Community and Groupware in Geocache Creation and Maintenance, Proc. CHI 2010, ACM Press (2010).

[3] Neustaedter, C., Tang, A., and Judget. T, Creating Scalable Location-Based Games: Lessons from Geocaching, Journal of Personal and Ubiquitous Computing, Springer (2012).

[4] O'Hara, K. Understanding Geocaching Practices and Motivations, Proc. CHI 2008, ACM Press (2008).

[5] SL Geocaching, http://slgeocaching.com 